\title{
Spinal muscular atrophy-progressive myoclonic epilepsy syndrome
}

INSERM

\section{Source}

INSERM. (1999). Orphanet: an online rare disease and orphan drug data base. Spinal muscular atrophy-progressive myoclonic epilepsy syndrome. ORPHA:2590

Spinal muscular atrophy-progressive myoclonic epilepsy syndrome is characterized by hereditary myoclonus and progressive distal muscular atrophy. Less than 10 cases have been reported. Treatment with clonazepam results in complete and lasting improvement of the myoclonus. 